Trusting information from friends:

Adults expect it but preschoolers do not

\author{
Narges Afshordi*, Melissa Koenig \\ Institute of Child Development, University of Minnesota
}

This version of the paper has been submitted for peer review. Comments and questions are encouraged and can be sent to afshordi@umn.edu.

We wish to thank Naomi Scmeck, Lucie Han, Holly Hames, George Budzius, Shelby Johnson, Sydney Cheung, Mehrnaz Mirhosseini, Sara Wilkerson, and Joanne Jung for their assistance in recruitment and data collection. We are grateful to Faith VanMeter, Lauren Eales, and Isabella Stallworthy for contributing to our video stimuli. We also thank the children and families, as well as adult participants, who took part in our studies. 


\begin{abstract}
It often seems easier to trust information from friends than strangers. Do preschoolers and adults expect such bias towards friends? Presented with a main character, her best friend, and a stranger, participants judged who was worthy of trust from the main character's perspective (third-person) as well as their own (first-person). Adults ( $n=128,55$ female) expected the main character to trust her friend even if she had been previously inaccurate, while basing their own judgments on accuracy. In contrast, four- and five-year-olds ( $n=128,62$ female) thought that the main character would be like themselves and care only about accuracy. Thus, while adults incorporate both friendship and accuracy into trust judgments, preschoolers fail to see that friendship matters.
\end{abstract}

Keywords: friendship, trust in testimony, selective trust 


\section{Trusting information from friends: Adults expect it but preschoolers do not}

As humans, we are lifelong traders of information. We learn from and convey information about every possible aspect of life, contributing to and benefitting from the cumulative cultural evolution taking place amongst us (Mesoudi \& Thornton, 2018). Children too are immersed in social learning from a young age (Gelman, 2009; Tomasello, 2016), building concepts, amassing knowledge, and acquiring skills. This marvelous ability of socially gaining information allows us to build on the knowledge of others and past generations, widening our world from the narrow slice that we experience through our senses to the whole planet and beyond. And yet, the very social learning capacities that ensure our success as a species also fail us spectacularly much of the time. Our trust in the words of others can lead us to believe in things that are false and completely cut off from reality (O'Connor \& Weatherall, 2019). For instance, persistent anti-vaccination attitudes are now a global phenomenon (Hornsby, Harris, \& Fielding, 2018), and have recently extended to alarming levels of distrust in a vaccine for COVID-19 (Taylor et al., 2020).

Why do we believe false information? Given that information and attitudes spread in social networks (e.g. Levy Paluck, 2011), part of the reason may be our social motivation to collaborate with trusted individuals by accepting their claims, especially those who are dear and near to us. That is, we may be less skeptical and more open to information when close social sources invite us to believe them. In fact, $17 \%$ of participants in a survey said they would accept "anything a friend shares on social media as fact and impossible to be false because it is from someone they know well" ("Many trust friends", 2019). Across three experiments, we collect empirical evidence for the existence of an intuition of bias towards friends among adults and examine whether preschoolers also hold and harbor such expectations about others. First, we describe previous work on friendships and social learning in young children.

Children have stable and often enduring friendships from a young age that center on shared play (Dunn, 1993; Howes, 1988; 2009; Hartup, 2006). While the significance of play may 
make early friendships seem superficial, they are in fact rich relationships built on coordinated communication and deft maneuvering of conflicts (Gottman, 1989). In addition to seeking and maintaining friends, children conceptualize friendship in the abstract sense and make inferences about others' friendship patterns based on a variety of cues, including but not limited to meaningful proximity, similarity, and prosocial interactions (Afshordi \& Liberman, 2020; Afshordi, 2019; Liberman \& Shaw, 2017; 2018). This means that they are able to think and reason about other people's friendships. Furthermore, preschoolers expect friendship to breed bias, manifesting in sharing of material resources (Olson \& Spelke, 2008; Liberman \& Shaw, 2017), as well as gossip: even three-year-olds expect people to speak favorably of their friends (Liberman \& Shaw, 2020). As children get older, their knowledge of bias matures. For instance, by ages 6 to 8 , children are conscious of partiality in judgments, distrusting judges who rule in favor of their friends and against their enemies compared to those whose rulings mismatch their relationships (Mills \& Grant, 2009; Mills, Al-Jabari, \& Archaki, 2012). Thus, young children are both avid participants in and thoughtful observers of friendship, and understand many of the ways that friendship biases affect social judgments.

When it comes to learning information from others, children are selective. A rich literature has shown that children factor in epistemic accuracy when choosing who to learn from, trusting those that are more likely to have correct knowledge (e.g. Koenig, Clement, \& Harris, 2004; Koenig \& Harris, 2005; Koenig, Tiberius, \& Hamlin, 2019; Sobel \& Finiasz, 2020). In parallel, children also prefer to learn from individuals based on their interpersonal or social characteristics, such as one's manner of address, being a native speaker, or a prosocial agent (Li \& Koenig, 2020; Kinzler, Corriveau, \& Harris, 2011; Lane, Wellman, \& Gelman, 2013). While establishing trust based on epistemic or social grounds depends on the specific features at play, a recent meta-analysis suggests that four- to six-year-olds generally prioritize epistemic cues over social ones when the two are in competition (Tong, Wang, \& Danovitch, 2019). Within the context of social cues as the basis of epistemic trust, there is evidence that children's default is 
to trust information from close social partners, such as their mother (Corriveau et al., 2009), a familiar teacher (Corriveau \& Harris, 2009), or group members (Elashi \& Mills, 2014).

Given that preschoolers 1) have conceptions of friendship, 2) recognize bias to some extent, and 3) are selective learners who sometimes privilege information from close social partners, do they also expect that people will likely trust testimony from their friends? Specifically, we ask if 4- and 5-year-olds and adults think that people tend to believe their friends over strangers, and if so whether they expect this trust to persist if the friend is a poor source of information. In order to test this, we contrast a situation in which a main character's friend has a history of accuracy (i.e. the accurate friend is contrasted with an accurate stranger) to one in which she does not (i.e. the inaccurate friend is contrasted with an accurate stranger), and ask if the person's trust in her friend would be modulated by accuracy information. Further, we ask if children and adults distinguish their own perspective from that of the main character in trusting information from the friend versus stranger. The inclusion of both first-person and thirdperson perspectives in documenting an understanding of bias is crucial. In order to show that interpersonal biases are understood to be rooted in the specific relationship that holds between two people (i.e., friendship), we asked participants to predict whose information--the friend's or the stranger's--would be sought and accepted both within and outside of the friendship relationship. By comparing the main character's third-person perspective with participants' own first-person judgments, we tested whether children and adults take the friendship between the main character and the friend into account when predicting what the main character will do (third-person) and when judging what to do for oneself (first-person). To recognize that others trust their friends is to expect them to trust their friend (because of friendship) while not doing so yourself (because of lack of friendship). Thus, if children distinguish between the two perspectives, they have shown their true understanding of bias towards friends.

Experiment 1 asks these questions in the context of labels for novel objects, testing if preschoolers and adults expect others (in third-person contexts), but not themselves (in first- 
person contexts), to believe their friends. In third-person contexts, if participants view friendship as a reason to trust, they should expect the main character to endorse information from her friend over information from the stranger. If, however, participants fail to see the influence of friendship, their judgments on behalf of the main character will be split between the friend and the stranger. In order to assess participants' understanding of the force of this bias, our experiments also lay out a conflict between accuracy on the one hand and friendship on the other. If participants see friendship biases as strong enough to overwhelm epistemic information such as accuracy, they should expect the main character to trust her friend for information, even when the friend has been inaccurate. However, if they view accuracy as a limiting factor on friendship biases, they should expect the main character to trust an accurate stranger over the friend who has been inaccurate in the past.

In Experiment 2, we change the type of information under study from labels to opinions. By having the friend and the stranger offer up opinions, which are inherently subjective, we give children another opportunity to demonstrate recognition of the epistemic favor that friends may show towards each other. If children expect the main character to trust her friend for facts in Experiment 1, we expect them to do so in equal or greater measure for opinions. If children do not show an expectation that the main character will trust her friend in Experiment 1, they may do so yet for opinions in Experiment 2. Finally, if they do not think that friends are prone to believing each other over strangers, they will not judge the main character as more likely to believe her friend in either experiment.

As mentioned above, we include adults in Experiment 1 both to record their intuitions and to compare them with those of preschoolers. Given that adults are more sophisticated in their thinking about bias, the third and final experiment tests their prescriptive judgments, as well as their predictions of who they would believe if they were in the main character's position. 


\section{Experiment 1}

The main goal of this experiment was to test whether children and adults expect a protagonist named Maya to be biased in seeking and endorsing claims from her friend, and if so whether they expect her to still do so when her friend is clearly a poor source of information. To test whether children's own learning decisions diverged from what they expected Maya to do, we asked questions from two perspectives: third-person (Maya) and first-person (the participant).

We pursued this goal in several ways. First, we asked participants who they or Maya would ask and endorse when presented with labels of novel objects. At the end of the task, we tested participants' memory of the labels they had endorsed earlier on to examine whether their memory of labels was different when assessed in the first- versus third-person perspectives. Second, we asked whom the participants and Maya would seek information from when specific knowledge or expertise was required. For instance, who would a friend (like Maya) and a nonfriend (the participant) consult in order to learn more about dinosaurs, or to fix a broken toy? Third, we examined whom children would choose for themselves and Maya when seeking public (e.g. the color of frogs) or personal knowledge (e.g. a person's favorite color). Recent work suggests that children reason about shared knowledge between people based on their relationship and the type of knowledge, but while three- to five-year-olds expect some connections between knowing secrets and friendship, they fall short of understanding the depth and nuances (Liberman, Gerdin, Kinzler, \& Shaw, 2020; Liberman \& Shaw, 2018; Liberman, 2020). Here, we were interested in whether children recognize the difference between the public sphere, in which everyone has access to impersonal information, and the personal sphere, in which only some have access to personal information by virtue of knowing the person.

Additionally, we tested children's inferences about social preferences between the two characters. If children demonstrated that the main character - Maya - preferred her friend and 
acted prosocially towards her, it would provide evidence that they had encoded the friendship and understood its social implications correctly.

Finally, given previous findings linking children's performance on trust in testimony to parental child-rearing values and social conformity (Reifen Tagar et al., 2014), these measures were included in an exploratory capacity. The goal here was to test whether parental authoritarianism or social conformity views would predict children's expectations about trust in friends for labels of novel objects.

\section{Method}

Participants. Sixty-four children aged four and five $(n=32$ four-year-olds, $n=32$ fiveyear-olds, $M=59.6$ months, 31 female) participated in the lab. Three additional participants were excluded for not completing the task (1), experimenter error (1), and technical failure (1). Participants were recruited from a database of local families interested in child development research. Although demographic information was not collected, data from $39 \%$ of the database is as follows: $86 \%$ White, $1 \%$ Black, $2 \%$ Asian, $11 \%$ mixed-race or other. The study was approved by the IRB at [__ ] Families received a $\$ 5$ reimbursement and children chose a small toy after participation. Additionally, 64 adults $(M=37$ years, 24 female, $80 \%$ White, $8 \%$ Black, $6 \%$ Asian, and 6\% mixed-race) were recruited from Amazon mTurk and participated online.

Materials. The stimuli included videos of three women wearing different colored t-shirts, as well as a number of pictures. Materials were presented to children on a Macbook with a covered keyboard. Parents responded to 4 items on the tendency towards authoritarian childrearing values (Feldman \& Stenner, 2005), and 17 items on their own values with regard to social conformity (Feldman, 2003). Adults participated through the survey platform, Qualtrics.

Design. Participants were randomly assigned to either the Friendship condition (accurate friend vs. accurate stranger), or the Inaccurate Friend condition (inaccurate friend vs. accurate stranger). Each condition had 16 orders across which we counterbalanced: identity of 
the friend (person on the left of right), order of perspectives for Ask and Endorse trials (Maya's perspective first or second), order of the Public and Personal trials (Public first or second), and order of Social preference and Expert knowledge blocks (Social preference first or second).

Procedure. The experiment consisted of two phases: a familiarization phase and test phase. See Table 1 for an overview of the procedure for all experiments.

Familiarization phase. Participants watched an Introduction video that began with all three characters waving at the camera. The main character introduced herself as Maya and then indicated one of the others, saying, "This is my best friend Jenny. Jenny and I have been friends for a long time. We go to the same school and we like doing everything together." She then indicated the third person and said, "This is Sophie, and I met her just a few minutes ago. Sophie goes to a different school. She seems nice but I don't know anything about her."'

Next, participants watched a Naming video in which Maya brought out familiar objects (spoon, cup, ball, duck) one by one, held them up while looking into the camera and said, "Check this out!" She placed the object on a stand in front of her and continued, "I wonder what this is called." The side characters then spoke up in turn naming the object. In the Friendship condition, both the friend and the stranger named all objects correctly. In the Inaccurate Friend condition, the stranger named the objects correctly, but the friend named them incorrectly (calling the spoon a "boat", the ball a "hat", the cup a "book", the duck a "shoe").

Test phase. This phase included six sets of questions for children and seven for adults.

1. Ask and Endorse (6 trials). For a block of three trials, participants answered from their own perspective (i.e. first-person). For another block of three trials, we asked about Maya's perspective (i.e. third-person). To make this clear, a picture of a hand pointing at the camera (first-person) or to Maya (third-person) was displayed at the start of each block. This was reinforced by an explicit statement, "I'm going to ask some questions about what [you think]/[Maya thinks]." 
In each trial, participants watched Maya bring out a novel object. Similar to the Naming video, she displayed it and wondered what it was called. Before the side characters spoke, however, the experimenter posed an Ask question (Participant's perspective: "Let's find out what this is called. Who do you want to ask?" Maya's perspective: "Maya wants to know what this is called. Who do you think she's going to ask?"). After the participant's response, the side characters offered different novel labels. The experimenter then asked an Endorse question ("Sophie called this a wug and Jenny called this a dax." Participant's perspective: "What do you think it's called?" Maya's perspective, "What will Maya think it's called?")

2. Public and Personal knowledge (6 trials). In these trials, participants made judgments about who (friend or stranger) would know a piece of information that was: 1) Public, meaning information that everyone has access to (what bunnies like to eat, what color frogs are, what the best season for the beach is), and 2) Personal, meaning information that only people who know Maya well have access to (Maya's favorite food, favorite color, birthday month).

3. Expert knowledge (6 trials). Participants answered who would be consulted for questions that required expertise over a body of knowledge or skill. They did this from their own perspective (who the participant would ask about seahorses, to fix their broken toy, or teach them new songs), and from Maya's perspective (who Maya would ask about dinosaurs, to fix her broken toy, or teach her new songs).

4. Social preference (6 trials). We asked participants for preferences between the friend and stranger from their own perspective and Maya's (who they/Maya like best, would share with, would help).

5. Control questions (3 trials). These irrelevant questions with unknowable answers were asked to test whether participants had an overwhelming preference for the friend or the stranger no matter what the issue was (who likes pasta more than sandwiches, who lives in the house with a black and not white door, who rides a bus to school and not a bike). 
6. Label memory (6 trials). We probed participants' memory of the novel object labels. They were reminded of the perspective associated with each block of objects ("We're going to see some of the things we saw before. When we saw them before, I asked you what [Maya thinks]/[you think] they're called. Let's see if you remember.") and had to choose one of two labels for each object (e.g. "What [does Maya]/[do you] think this is called? A wug or a dax?")

Table 1

Overview of procedure for all experiments. $X$ signifies that the component was included

\begin{tabular}{|c|c|c|c|}
\hline $\begin{array}{c}\text { Experiment } \\
\text { (Participant ages) }\end{array}$ & $\begin{array}{c}1 \\
\text { (Children \& Adults) }\end{array}$ & $\begin{array}{c}2 \\
\text { (Children) }\end{array}$ & $\begin{array}{c}3 \\
\text { (Adults) }\end{array}$ \\
\hline \multicolumn{4}{|l|}{ 1. Familiarization phase: } \\
\hline Introduction video & $x$ & $x$ & $x$ \\
\hline Vicarious manipulation & & & Vicarious condition \\
\hline Naming video & $x$ & $x$ & $x$ \\
\hline Memory checks & $x$ & $x$ & $x$ \\
\hline \multicolumn{4}{|l|}{ 2. Test phase: } \\
\hline Ask \& Endorse & For labels & For opinions & For labels \\
\hline Public \& Personal Knowledge & $x$ & & \\
\hline Expert knowledge & $x$ & & \\
\hline Social preference & $x$ & $x$ & $x$ \\
\hline Control questions & $x$ & $x$ & \\
\hline Label memory & $x$ & & \\
\hline Final Memory checks & $x$ & $x$ & \\
\hline Justifications & Only for adults & & $x$ \\
\hline
\end{tabular}

7. Justifications - Adults only (2 trials). Participants viewed Naming videos for two further novel objects. An Endorse question was asked while the Ask question was omitted. One trial 
was from the participant's own perspective, while the other was from Maya's. Importantly, we asked participants to explain the reasoning behind their endorsement.

At the very end, we used the same wording as before to test memory for the relationships (friend and stranger), and speaker accuracy (Inaccurate friend condition only).

Coding. In all experiments, choices for the friend were coded as 1 and choices for the stranger were coded as 0 .

\section{Results}

Familiarization phase. Almost all participants remembered the identity of the friend and stranger ( $94 \%$ of children, $98 \%$ of adults). In the Inaccurate Friend condition, all children and adults remembered which character had been correct and which one had been wrong.

Test phase. For each set of questions, several mixed-model binary logistic regression models were fit to the data using the glmer function from the package Ime4 in R (2020). These models included the variables of interest (e.g. condition, perspective, age group) and combinations of their interactions as fixed effects and participant as a random effect. The best model was selected based on comparisons between nested models using the anova function. To compare performance against chance, regression models including only the intercept as a fixed effect and participant as a random effect were run on responses in each of the conditions and perspectives (or sphere in the case of Public and Personal knowledge) for each set of questions. In order to deal with multiple comparisons, a Holm-Bonferroni correction was applied to p-values from children's comparisons against chance, and separately to those from adults.

1. Ask and Endorse. These questions asked participants who they or Maya would ask and endorse labels from for novel objects. See Figure 1 for a graph of children's and adults' responses. We initially tested for possible differences between Ask and Endorse questions, but found none $(p=0.62)$, indicating that responses were comparable. All subsequent analyses collapsed Ask and Endorse responses $(\max =6)$. 
Combined responses from children and adults were analyzed using mixed-model binary logistic regressions. The best model found a three-way interaction between age group, condition, and perspective $(\mathrm{OR}=51.78 ; 95 \% \mathrm{Cl}=14.64,201.49 ; p<0.0001)$. Following up on this, we ran separate mixed-model regressions on the child and adult data that included condition, perspective, and their interaction. For children, there was a significant effect of condition $(\mathrm{OR}=0.35 ; 95 \% \mathrm{Cl}=0.17,0.69 ; p=0.002)$, but no effect of perspective and no interaction between the two. This indicated that children in the Inaccurate Friend condition $(M=$ $36.2 \%)$ chose the friend less often than those in the Friendship condition $(M=54.3 \%)$. For adults, there was a significant interaction between condition and perspective (OR $=0.01,95 \%$ $\mathrm{Cl}=0,0.04 ; p<0.0001)$, indicating that divergence between responses from Maya's and the self's perspective were larger in the Inaccurate Friend condition than in the Friendship condition.

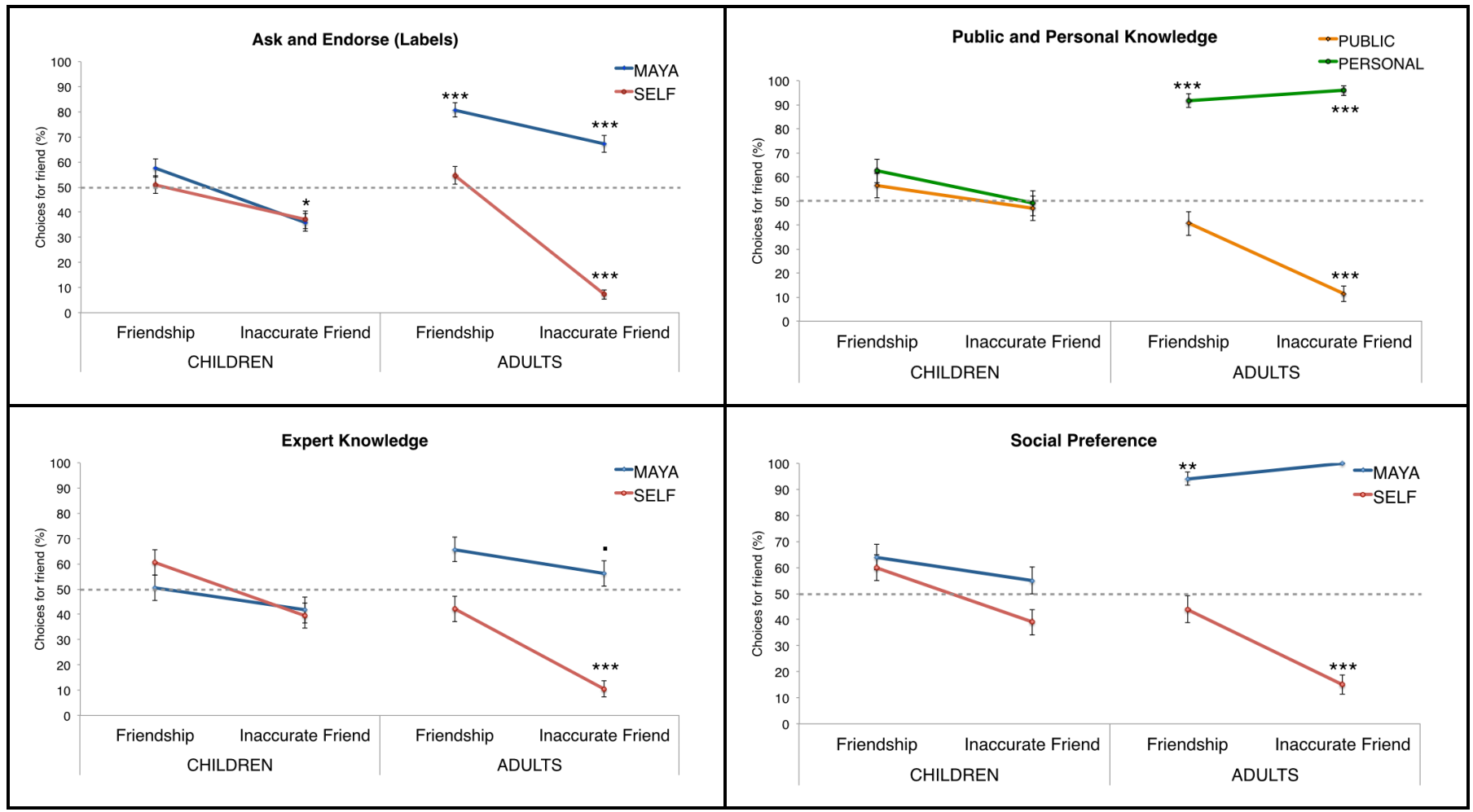

Figure 1. Responses from children and adults in Experiment 1, separated by condition for 1)

Ask and Endorse questions combined (top left) 2) Public and Personal knowledge questions (top right) 3) Expert knowledge questions (bottom left) and 4) Social preference questions 
(bottom right). Responses are separated by perspective for Ask and Endorse, Expert

knowledge, and Social preference trials (Maya = blue lines, Self = red lines), and by sphere type for Public and Personal knowledge (Public = green lines, Personal = orange lines $)$. Error bars reflect standard error of the mean. Dotted lines show chance level. Results of comparison of performance against chance are noted $\left(. p<.1,{ }^{*} p<.05,{ }^{* *} p<.01,{ }^{* * *} p<.001\right)$.

Comparisons against chance revealed that children's responses in the Friendship condition were at chance (see Table 2), meaning that they were not biased towards the friend and did not expect Maya to be biased either. In contrast, and in line with the main effect of condition reported above for children, responses in the Inaccurate friend condition were significantly below chance, from both the child's and Maya's perspective. In contrast, adults judged that Maya would side with her friend at rates significantly above chance in the Friendship condition, while judgments for themselves were at chance. In the Inaccurate Friend condition, adults still thought that Maya would trust her friend with higher than chance likelihood, but were significantly less likely than chance to trust the friend themselves.

Table 2

Ask and Endorse responses (Exp. 1) and p-values from their comparison against chance

\begin{tabular}{|c|c|c|c|c|c|c|c|c|}
\hline $\begin{array}{l}\text { Age } \\
\text { Group }\end{array}$ & Condition & Perspective & $\begin{array}{l}\text { Choice of } \\
\text { friend (\%) }\end{array}$ & $p$-value & Condition & Perspective & $\begin{array}{l}\text { Choice of } \\
\text { friend (\%) }\end{array}$ & $p$-value \\
\hline \multirow{2}{*}{ Children } & \multirow{2}{*}{ Friendship } & Maya & $58 \%$ & 0.13 & \multirow{2}{*}{$\begin{array}{l}\text { Inaccurate } \\
\text { Friend }\end{array}$} & Maya & $36 \%$ & 0.014 \\
\hline & & Self & $51 \%$ & 0.9 & & Self & $37 \%$ & 0.024 \\
\hline \multirow{2}{*}{ Adults } & \multirow{2}{*}{ Friendship } & Maya & $81 \%$ & 0.0002 & \multirow{2}{*}{$\begin{array}{l}\text { Inaccurate } \\
\text { Friend }\end{array}$} & Maya & $67 \%$ & $<0.0001$ \\
\hline & & Self & $55 \%$ & 0.4 & & Self & $7 \%$ & .0001 \\
\hline
\end{tabular}

We ran two binary logistic regression models to test whether parental authoritarianism or conformity predicted children's responses. Each model also included condition, perspective, and 
their interaction as fixed effects and participant as a random effect. There was neither a significant effect of parental authoritarianism $(p=0.54)$, nor of parental conformity $(p=0.7)$.

2. Public and Personal knowledge. These questions asked who would know information that was either publicly available (e.g. color of frogs) or personal (e.g. Maya's birthday). See Figure 1 for a graph of the results. We found a significant three-way interaction between age group, condition, and sphere type $(\mathrm{OR}=27.77 ; 95 \% \mathrm{Cl}=4.35,206.68 ; p=0.0007)$. Follow-up analyses found that for children, there was no main effect of condition or sphere type, nor any interaction between the two. For adults, there was a significant interaction between condition and sphere type $(\mathrm{OR}=0.04 ; 95 \% \mathrm{Cl}=0.01,0.23 ; p=0.0006)$, indicating that choices diverged more in the Inaccurate Friend condition than in the Friendship condition.

Comparing performance against chance for children revealed that responses were consistently at chance level regardless of condition or information type (see Table 3). Adults, however, were significantly more likely than chance to choose the friend in response to questions about personal information in both conditions. For public information, adults were at chance level in the Friendship condition and below chance in the Inaccurate Friend condition.

Table 3

Public \& Personal knowledge responses (Exp. 1) and p-values from comparison against chance

\begin{tabular}{|c|c|c|c|c|c|c|c|c|}
\hline $\begin{array}{l}\text { Age } \\
\text { Group }\end{array}$ & Condition & Sphere & $\begin{array}{l}\text { Choice of } \\
\text { friend }(\%)\end{array}$ & $p$-value & Condition & Sphere & $\begin{array}{l}\text { Choice of } \\
\text { friend }(\%)\end{array}$ & $p$-value \\
\hline \multirow{2}{*}{ Children } & \multirow{2}{*}{ Friendship } & Personal & $62 \%$ & 0.24 & \multirow{2}{*}{$\begin{array}{l}\text { Inaccurate } \\
\text { Friend }\end{array}$} & Personal & $49 \%$ & 1 \\
\hline & & Public & $56 \%$ & 0.98 & & Public & $47 \%$ & 1 \\
\hline \multirow{2}{*}{ Adults } & \multirow{2}{*}{ Friendship } & Personal & $92 \%$ & $<0.0001$ & \multirow{2}{*}{$\begin{array}{l}\text { Inaccurate } \\
\text { Friend }\end{array}$} & Personal & $96 \%$ & $<0.0001$ \\
\hline & & Public & $41 \%$ & 0.11 & & Public & $11 \%$ & $<0.0001$ \\
\hline
\end{tabular}

3. Expert knowledge. These trials tested reasoning about who would have expertise in a particular domain (e.g. "Who will you ask to tell you about seahorses?") Due to an error in the 
Qualtrics survey, only 38 out of 64 adults had responses from their own perspective.

Nevertheless, combined child and adult data were analyzed using mixed-model binary logistic regressions. The best model found a main effect of condition $(\mathrm{OR}=0.44 ; 95 \% \mathrm{Cl}=0.25,0.75 ; p$ $=0.003)$ and an interaction between age group and perspective $(\mathrm{OR}=7.05,95 \% \mathrm{Cl}=3.31$, 15.39; $p<0.0001)$. Follow-up regression on the child data found only a marginally significant effect of condition $(\mathrm{OR}=0.41,95 \% \mathrm{Cl}=0.15,1.01 ; p=0.052)$, indicating that children were choosing the friend somewhat less in the Inaccurate Friend condition compared to Friendship. For adults, there was a significant interaction between condition and perspective $(O R=0.24$; $95 \% \mathrm{Cl}=0.07,0.78 ; p=0.02$ ), indicating that the distance between responses from their own view and Maya's was higher in the Inaccurate Friend condition than in the Friendship condition. Comparisons against chance found that children's responses about Expert knowledge were statistically at chance for all conditions and perspectives (see Table 4). In other words, children chose the friend or stranger equally for themselves and Maya when judging who would have expertise. Adults chose the friend marginally more than chance when answering who Maya would ask in the Friendship condition, even though they did not prefer the friend for themselves. In the Inaccurate Friend condition, adults trusted the accurate stranger over the inaccurate friend, but expected Maya to be torn between her friend and stranger.

Table 4

Expert knowledge responses (Exp. 1) and p-values from their comparison against chance

\begin{tabular}{|c|c|c|c|c|c|c|c|c|}
\hline $\begin{array}{l}\text { Age } \\
\text { Group }\end{array}$ & Condition & Perspective & $\begin{array}{l}\text { Choice of } \\
\text { friend (\%) }\end{array}$ & $p$-value & Condition & $\begin{array}{l}\text { Perspectiv } \\
e\end{array}$ & $\begin{array}{l}\text { Choice of } \\
\text { friend (\%) }\end{array}$ & $p$-value \\
\hline \multirow{2}{*}{ Children } & \multirow{2}{*}{ Friendship } & Maya & $51 \%$ & 0.93 & \multirow{2}{*}{$\begin{array}{l}\text { Inaccurate } \\
\text { Friend }\end{array}$} & Maya & $42 \%$ & 0.38 \\
\hline & & Self & $60 \%$ & 0.3 & & Self & $40 \%$ & 0.3 \\
\hline \multirow{2}{*}{ Adults } & \multirow{2}{*}{ Friendship } & Maya & $66 \%$ & 0.052 & \multirow{2}{*}{$\begin{array}{l}\text { Inaccurate } \\
\text { Friend }\end{array}$} & Maya & $56 \%$ & 0.47 \\
\hline & & Self & $42 \%$ & 0.47 & & Self & $11 \%$ & $<0.0001$ \\
\hline
\end{tabular}


4. Social preference. These trials probed a social preference between the friend and stranger (liking, helping, sharing) from first- and third-person perspectives. Analyzing pooled responses for children and adults revealed a significant interaction between age group and perspective $(\mathrm{OR}=80.05 ; 95 \% \mathrm{Cl}=18.41,418.72 ; p<0.0001)$, indicating that the divergence in responses between first- and third-person perspectives was larger for adults than it was for children. When considering the child and adult data independently, the best models found only a significant effect of perspective (children: $\mathrm{OR}=0.5 ; 95 \% \mathrm{Cl}=0.29,0.85 ; p=0.009$; adults: OR $=0.01 ; 95 \% \mathrm{Cl}=0,0.02 ; p<0.0001)$, indicating that both children and adults chose the friend as a social partner more when answering from Maya's perspective than their own.

Comparison of responses to chance found children statistically at chance regardless of condition or perspective (see Table 5). Despite this, in response to the "Who does Maya like best?" question, children chose the friend significantly more often than chance in both conditions according to binomial tests (Friendship: $26 / 32, p=0.0005$; Inaccurate Friend condition: $25 / 32, p=0.002)$. In contrast, adults almost unanimously thought that Maya would prefer her friend regardless of whether she had been previously accurate or inaccurate. For themselves, adults chose the friend and stranger equally in the Friendship condition, but were significantly less likely than chance to prefer the friend in the Inaccurate Friend condition.

Table 5

Social preference responses (Exp. 1) and p-values from their comparison against chance

\begin{tabular}{|c|c|c|c|c|c|c|c|c|}
\hline $\begin{array}{l}\text { Age } \\
\text { Group }\end{array}$ & Condition & Perspective & $\begin{array}{l}\text { Choice of } \\
\text { friend (\%) }\end{array}$ & $p$-value & Condition & Perspective & $\begin{array}{l}\text { Choice of } \\
\text { friend (\%) }\end{array}$ & $p$-value \\
\hline \multirow{2}{*}{ Children } & \multirow{2}{*}{ Friendship } & Maya & $64 \%$ & 0.17 & \multirow{2}{*}{$\begin{array}{l}\text { Inaccurate } \\
\text { Friend }\end{array}$} & Maya & $55 \%$ & 0.37 \\
\hline & & Self & $60 \%$ & 0.37 & & Self & $39 \%$ & 0.37 \\
\hline \multirow{2}{*}{ Adults } & \multirow{2}{*}{ Friendship } & Maya & $94 \%$ & 0.002 & \multirow{2}{*}{$\begin{array}{l}\text { Inaccurate } \\
\text { Friend }\end{array}$} & Maya & $100 \%$ & $\mathrm{~N} / \mathrm{A}$ \\
\hline & & Self & $44 \%$ & 0.37 & & Self & $15 \%$ & $<0.0001$ \\
\hline
\end{tabular}


5. Control questions. These questions tested for an overwhelming preference in favor of one character over the other. There was no effect of age group or condition nor any interaction between the two for responses to control questions. Importantly, adults and children in both conditions responded at chance level (children: Friendship: $54 \%, p=0.44$, Inaccurate Friend: $48 \%, p=0.68$; adults: Friendship: 48\%, $p=0.68$, Inaccurate Friend: 49\%, $p=0.84$ ).

6. Label memory trials. These questions tested participants' memory of the labels they had endorsed earlier, either from their own perspective or Maya's. See Figure 2 for graph of results. A score of 1 meant that the response for the memory trial matched the endorsed label from before, and a score of 0 meant that the two responses did not match. Due to an error in the Qualtric survey, all adult participants had at least one response but no one had their full 6 responses. As a result, only $50 \%$ of possible adult label memory responses were available.

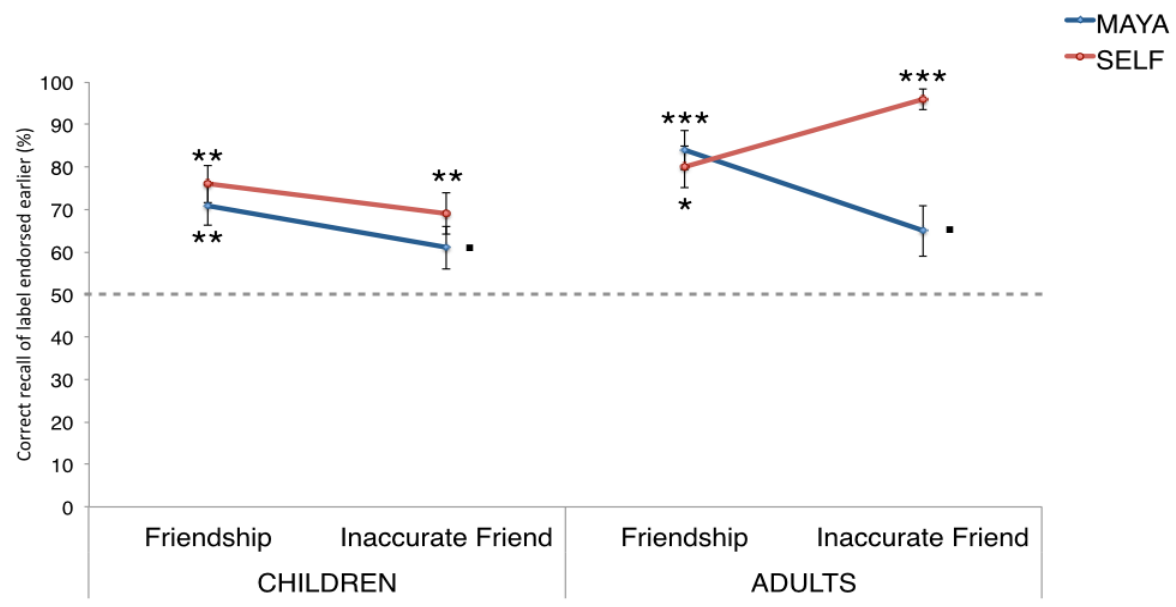

Figure 2. Label memory responses from children and adults in Experiment 1, separated by condition and perspective. Error bars reflect standard error of the mean. Dotted lines show chance level. Results of comparison of performance against chance are noted $\left(. p<.1,{ }^{*} p<.05\right.$, $\left.{ }^{* *} p<.01,{ }^{* * *} p<.001\right)$.

Generally, both children and adults remembered most of the labels they had endorsed (responses always above $60 \%$, see Table 6). Analyzing the combined adult and child data 
revealed main effects of age group $(\mathrm{OR}=0.47 ; 95 \% \mathrm{Cl}=0.27,0.78 ; p=0.004)$ and perspective $(\mathrm{OR}=1.66 ; 95 \% \mathrm{Cl}=1.12,2.5 ; p=0.013)$, but no effect of condition nor any interactions. Considering the child data independently, there was no significant effect of perspective or condition. For adults, there was a significant interaction between perspective and condition (OR $=22.09 ; 95 \% \mathrm{Cl}=3.34,225.28 ; p=0.003)$, indicating that while memory for the self's and Maya's labels was comparable in the Friendship condition, memory was significantly better for self than for Maya in the Inaccurate Friend condition.

As shown in Table 6, comparing performance against chance showed that for both children and adults, memory was almost always significantly better than chance. The only exceptions where memory was marginal but not significant were labels from Maya's perspective in the Inaccurate Friend condition, indicating that participants were somewhat less likely to encode the label they thought Maya was learning from her inaccurate friend, perhaps because they thought that she was learning false information.

Table 6

Label memory responses (Exp. 1) and p-values from their comparison against chance

\begin{tabular}{|c|c|c|c|c|c|c|c|c|}
\hline $\begin{array}{l}\text { Age } \\
\text { Group }\end{array}$ & Condition & Perspective & $\begin{array}{l}\text { Choice of } \\
\text { friend (\%) }\end{array}$ & $p$-value & Condition & Perspective & $\begin{array}{l}\text { Choice of } \\
\text { friend } \\
\text { (\%) }\end{array}$ & $p$-value \\
\hline \multirow{2}{*}{ Children } & \multirow{2}{*}{ Friendship } & Maya & $71 \%$ & 0.004 & \multirow{2}{*}{$\begin{array}{l}\text { Inaccurate } \\
\text { Friend }\end{array}$} & Maya & $61 \%$ & 0.051 \\
\hline & & Self & $76 \%$ & 0.001 & & Self & $69 \%$ & 0.004 \\
\hline \multirow{2}{*}{ Adults } & \multirow{2}{*}{ Friendship } & Maya & $84 \%$ & $<0.001$ & \multirow{2}{*}{$\begin{array}{l}\text { Inaccurate } \\
\text { Friend }\end{array}$} & Maya & $65 \%$ & 0.09 \\
\hline & & Self & $80 \%$ & 0.027 & & Self & $96 \%$ & $<0.0001$ \\
\hline
\end{tabular}

7. Justifications-Adults only. Justifications were coded as relating to friendship, accuracy, or other (see Appendix A for detailed results). Adults explained Maya's trust in her friend by 
simply appealing to friendship in both the Friendship and Inaccurate Friend conditions.

Meanwhile, they were more likely to explain their own trust in terms of accuracy.

At the end, $86 \%$ of children and $95 \%$ of adults identified the friend and stranger, and $81 \%$ of children and $97 \%$ of adults in the Inaccurate Friend condition remembered who had initially offered correct and incorrect labels during familiarization.

\section{Discussion}

This experiment asked whether children and adults expect others to trust information from a friend over a stranger, and whether they expect accuracy to affect this trust. Adults factored both prior accuracy and friendship into their judgments. When reasoning from Maya's vantage point, they expected her to choose the friend regardless of her prior accuracy. When answering for themselves, however, adults valued accuracy, and endorsed and remembered information from the accurate stranger. They were impartial between the friend and the stranger in the Friendship condition--after all, the friend was not their friend so they had no particular reason to favor either the friend or the stranger. Children did not expect Maya to be biased to believe her friend. Indeed, children's responses diverged from adults in that they seemed to care more about accuracy than friendship by making similar accuracy-based judgments for themselves and for Maya.

One example of this divergence between children and adults manifested in questions about Public and Personal knowledge. Children were equivocal between the friend and stranger in both conditions and from both perspectives. Adults, on the other hand, thought that Maya's friend would be highly likely to know personal information about her, yet highly unlikely to know the answer to simple general knowledge questions if she had been inaccurate in the past. Thus, adults seem to think that it would be impossible for the stranger to know personal details about Maya, and so the friend, however confused and muddled she may be in general, would still be more likely to know such information. With regard to Expert knowledge questions too, responses echo those of Ask and Endorse trials. Children trended towards valuing accuracy but 
not friendship from both perspectives, while adults valued friendship when answering from Maya's perspective. Thus, for Ask and Endorse trials, Public and Personal knowledge, and Expert knowledge, friendship was of consequence to adults and not children.

Finally, children and adults responded similarly for Social preference questions in that both groups chose the friend more when answering from Maya's perspective compared to their own, although the divergence between self and Maya's perspective was larger for adults than for children. At the very least, this findings shows that children understood the perspective manipulations correctly. This rules out concerns that children's lack of discrimination between the two perspectives on previous questions (e.g. Ask and Endorse) was due to the ineffectiveness of the perspective manipulation. It is worth noting that children's responses on the Social preference questions from Maya's perspective, while higher than from their own perspective, were still at chance. This is a somewhat surprising finding. However, children were indeed higher than chance at choosing the friend as the one that Maya liked best. This means that their responses to the sharing and helping questions were split between the friend and stranger. This may signal some children's expectation that Maya would try to welcome or befriend the stranger, perhaps because Maya said at the start of the experiment that the stranger "seemed nice".

Adult justifications revealed that they chose the friend when endorsing novel labels from Maya's perspective because they believed that she would be swayed by friendship. Meanwhile, they attributed their own trust in the accurate stranger to accuracy, and gave mostly irrelevant responses in the Friendship condition when there was neither friendship nor accuracy to go on. These justifications confirm the roles of friendship and accuracy in making trust judgments, but do not reveal why adults think that Maya would trust her inaccurate friend. Adults may think that trust in an inaccurate friend is not epistemically licensed but happens regardless because other people's judgment is unfortunately clouded when it comes to their friends. Alternatively, they may believe that people trust friends even when they are not good sources of information 
because that is what friends are obligated to do and should indeed do. We address this question directly in Experiment 3 and attempt to better distinguish between the disparaging and the prescriptive views that adults might have about friendship as a basis for belief.

First, we follow up on the finding that children did not expect Maya to be biased towards her friend. In Experiment 2, we tested whether children would expect such bias when asked to make judgments about a different type of information.

\section{Experiment 2}

Four- and five-year-olds in Experiment 1 failed to see that Maya would prefer her friend and thus react differently from themselves when seeking and endorsing information. One possible explanation for this is their prioritizing of epistemic reasons in their own learning (Tong, Wang, \& Danovitch, 2019). Perhaps their reliance on epistemic rather than social reasons means they are less likely to consider that others might prefer social reasons in some situations. Thus, in order to test the question of whether children recognize bias towards friends as thirdperson observers, we moved from the domain of labels in Experiment 1 to opinions in Experiment 2. Opinions are inherently subjective. What one person thinks is the best movie, hobby, or food can be justifiably different from another person's view. As such, prior accuracy in labeling objects is not relevant to the ability to have valid opinions. Because of this, an inaccurate informant is less likely to be penalized for said inaccuracy when the question under consideration is about opinions rather than facts. Thus, if children recognize others' bias towards their friends, it is more likely to surface in children's responses for opinions. Following a procedure similar to before, we assigned children to the Friendship and Inaccurate Friend conditions. At test, we provided two items of the same type (either books, food, or games) and asked participants who Maya would like to Ask an opinion from when seeking the best item, and whose opinion she would Endorse. Once again, we asked the same questions from their own perspective too. 
If children think that friends are biased to believe each other, they should respond to questions from Maya's perspective by choosing the friend. If they do so in both the Friendship and Inaccurate Friend conditions, it would provide particularly strong indication of their recognition of bias towards friends. If, however, they only do so in the Friendship condition (i.e. when the friend and stranger were both accurate), it would still constitute as evidence that children think people trust the opinions of their friends more than strangers. If, however, children choose the friend and stranger at similar rates in the Friendship condition when answering from Maya's perspective, this will provide evidence that they do not discern the influence of friends.

Separately, this experiment will shed light on whether children view accuracy as important for seeking and endorsing opinions. If children choose the friend more when she is accurate than when she is inaccurate, they are demonstrating that prior accuracy affects trustworthiness of opinions. If, however, they favor the friend or see the friend and stranger as similar, children would have disregarded inaccuracy when judging opinions.

\section{Method}

Participants. Sixty-four children ( $\mathrm{n}=32$ four-year-olds, $\mathrm{n}=32$ five-year-olds, $M=60.35$ months, 31 female) took part. Two additional participants were excluded due to experimenter error. Children were recruited from the same population as Experiment 1. Thirty-six children participated in-person in the lab. The remaining 28 participants completed the experiment online due to COVID-19 restrictions.

Materials. Videos and pictures for the familiarization phase, social preference, and control trials were identical to Experiment 1. For online sessions, an experimenter videoconferenced with the child and parent over Zoom, and stimuli were presented on slides.com, a platform that supports synchronous online presentations. As in Experiment 1, parental authoritarianism and conformity measures were administered.

Design. Children were divided between the Friendship $(n=33)$ and Inaccurate Friend $(n=31)$ conditions. Each condition had 12 orders across which we counterbalanced: identity of 
the friend (person on the left or right), order of perspectives for Ask and Endorse trials (Maya's perspective first or second), order of item types (e.g. books first, second, or third), and order of Social preference perspective (Maya's perspective first or second).

Procedure. The experiment consisted of two phases: familiarization and test.

Familiarization. Identical to Experiment 1, children viewed the Introduction video followed by the Naming video. Then, memory for relationships and accuracy (Inaccurate Friend condition) was probed, and the videos were repeated in cases of wrong responses.

Test. This phase included four sets of questions.

1. Ask and Endorse (6 trials). Each participant answered a block of three trials from their own perspective, and another block of three from Maya's. Within the perspectives, each of the trials showed a different type of item: books, food, or games. In each trial, pictures of two items appeared and the experimenter posed an Ask question (e.g. child's perspective, "Let's find out which one is the best book to read. Who do you want to ask?"; Maya's perspective, "Maya wants to know which one is the best book to read. Who do you think Maya is going to ask?") Following the child's response, she proceeded to tell them that the informants had differing opinions (e.g. "Jenny thinks this one is the best book to read, and Sophie thinks this one is the best book to read.") Then she posed the Endorse question (e.g. child's perspective, "Which one do you think is the best book?"; Maya's perspective, "Which one will Maya think is the best book?")

2. Social preference (6 trials). Like Experiment 1, children were asked who they/Maya liked best, would share with, and would help.

3. Control questions (3 trials). These trials were identical to Experiment 1.

Like before, children's memory of the relationships and accuracy (Inaccurate friend condition) was tested.

COVID-19 Online modifications. A number of changes were made to the procedure in order to accommodate online testing. Parents were asked ahead of time to be in a quiet area 
without distraction from siblings. At the start of the session, the experimenter instructed parents to not interfere in any way in children's responses. Right before starting the study, the experimenter turned off her camera, meaning that children could hear but not see her. Following the practice of color-coding options (Sheskin \& Keil, 2018), we used the informants' shirt colors in addition to their names to refer to them. At the start of the study, we tested children's recognition of these (orange, yellow). In order to clearly associate items (e.g. book) with characters, item and character pictures were set against a panel of the character's shirt color. In addition to the option of providing responses that referred to characters using names or colors, children could point on the screen. In these cases, which happened rarely, parents informed the experimenter of the child's choice using the alphabet letter next to the option.

\section{Results}

Familiarization phase. Overall, $88 \%$ of children remembered the identities of the friend and stranger (83\% in-person, $93 \%$ online). In the Inaccurate Friend condition, $68 \%$ of children (65\% in-person, $71 \%$ online) remembered who had given correct and incorrect labels. Thus, online participants appeared to be even more attentive than those tested in person.

\section{Test phase.}

1. Ask and Endorse. See Figure 3 for a graph of results. An initial mixed-model binary logistic regression including question type (Ask vs. Endorse) as a fixed effect and participant as a random effect found no effect of question type $(p=0.27)$. Therefore, Ask and Endorse responses were collapsed for all subsequent analyses.

A set of binary regression models including variations of condition, perspective, and location (in-person vs. online) and their interactions as fixed effects and participant as a random effect were run. The best model found a significant main effect of location $(\mathrm{OR}=1.74 ; 95 \% \mathrm{Cl}=$ $1.06,2.88 ; p=.027)$, and no other effects. That is, children's performance on the Ask and Endorse trials were statistically indistinguishable depending on condition and perspective, but children participating online chose the friend more than those participating at the lab. We 
followed up on the effect of location by comparing performance against chance. Despite the difference in performance between locations, children were statistically at chance in their choice of the friend in both cases (in-person: $44 \%, p=0.21$; online: $56 \%, p=0.21, p$-values corrected for multiple comparisons). We also ran separate comparisons against chance for responses from all children (in-person and online participants combined) depending on condition and perspective. All responses were statistically at chance level (all corrected $p$-values $=1$ ).

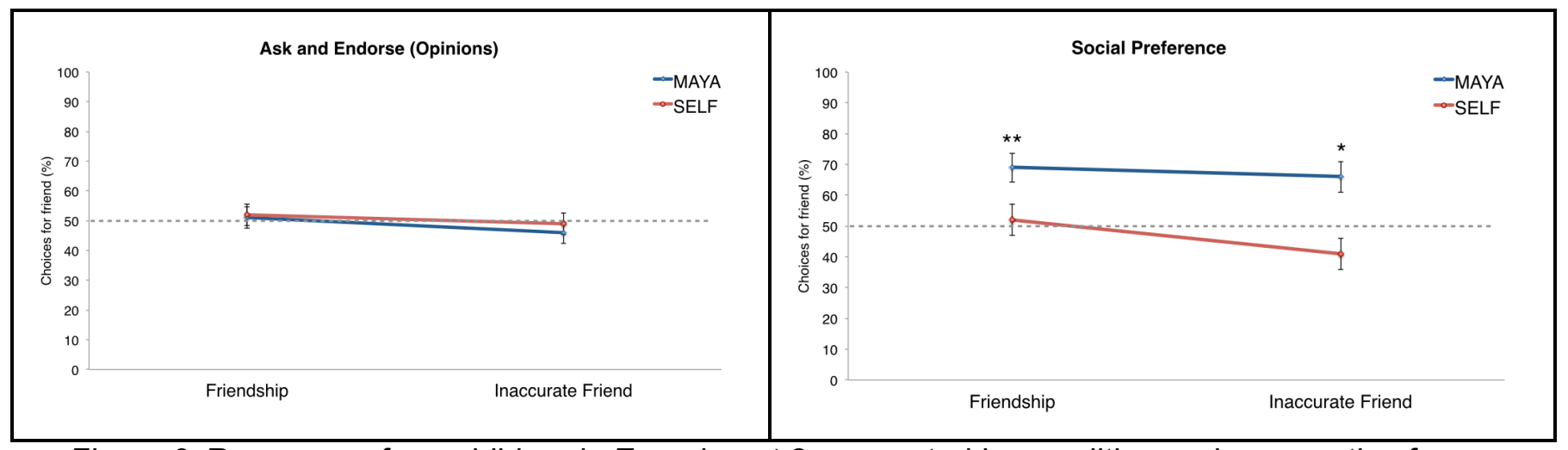

Figure 3. Responses from children in Experiment 2, separated by condition and perspective for

1) Ask and Endorse questions combined (left), 2) Social preference questions (right). Error bars reflect standard error of the mean. Dotted lines show chance level. Results of comparison of performance against chance are noted $\left({ }^{*} p<.05,{ }^{* *} p<.01\right)$.

Two models tested for prediction of Ask and Endorse responses from parental authoritarianism or conformity. These models included perspective, condition, and their interaction as fixed effects and participant as a random effect. There was no significant effect of parental authoritarianism $(p=0.09)$ or parental conformity $(p=0.31)$.

2. Social preference. See Figure 3 for social preference results. Several models including condition, perspective, and location were applied to the social preference responses. The best model found a significant main effect of perspective $(\mathrm{OR}=3.36 ; 95 \% \mathrm{Cl}=2.04,5.67$, $p<.0001$ ), indicating that children thought Maya would prefer her friend to the stranger to a 
greater degree than they themselves preferred the friend to the stranger. There was also a main effect of location $(\mathrm{OR}=2.87 ; 95 \% \mathrm{Cl}=1.27,6.82 ; p=.011)$, indicating that like Ask and Endorse trials, choices in favor of the friend were higher for children participating online compared to in-person. Follow-up comparisons against chance found responses from online participants to be above chance $(67 \%, p=0.006)$, while those from in-person participants were at chance $(49 \%, p=.88)$.

When compared to chance, children's responses from Maya's perspective were significantly above chance (Friendship condition: 69\%, $p=0.003$, Inaccurate Friend condition: $66 \%, p=0.017$ ), while those from their own perspective were at chance (Friendship condition: $52 \%, p=0.81$, Inaccurate Friend condition: $41 \%, p=0.39)$. As in Experiment 1, responses to who Maya liked were significantly above chance (Friendship: 28/33 choices for friend, $p<$ 0.0001; Inaccurate Friend condition: $26 / 31$ choices for friend, $p=0.001$, binomial tests).

3. Control questions. Responses were at chance in both conditions (Friendship: $45 \%$, $p=0.41 ;$ Inaccurate Friend: $41 \%, p=0.11$ ), and there was no difference between the conditions.

Most children remembered the relationships between Maya and the other characters ( $84 \%$ overall: $79 \%$ in-person, $89 \%$ online), as well as the accuracy of the friend and stranger in the Inaccurate Friend condition (77\% overall: $82 \%$ in-person, $71 \%$ online).

\section{Discussion}

This experiment asked if children expected others to trust opinions from their friends over those from strangers. Children's responses were consistently at chance level, meaning that children sought and endorsed the opinions of the friend and the stranger equally for themselves and for Maya, regardless of whether the friend had been accurate in the past or not.

These findings have three main implications. First, they suggest that four- and five-yearolds do not expect people to believe their friends over strangers. This is indicated by their lack of choosing the friend more from Maya's perspective, particularly in the Friendship condition 
across both Experiment 1 (labels, etc.) and Experiment 2 (opinions). Second, children do not appear to think that prior accuracy or lack thereof bears on the trustworthiness of an informant's opinion. This is indicated by similar responses across the two conditions. Finally, children's higher rates of choosing the friend when answering social preference questions from Maya's perspective compared to their own shows once again that they think people are likely to prefer and support their friends. In the next and final experiment, we turn back to adults in order to gain some traction on the reasoning behind their assumption of trust in friends.

\section{Experiment 3}

In Experiment 1, adults' justifications for Maya's trust in the friend mentioned friendship but did not make clear why they thought friendship led to trust in an inaccurate informant. One possibility is that adults think that people typically trust their friends even though they should not, as in the case of inaccuracy. In other words, they believe that this is what we do when dealing with information from our friends. Another possibility is that adults think people trust their friends because they should. They may think that part of being a good friend is believing your friends and having faith in their judgments about the world. Somewhat similar arguments have been made by philosophers who posit that the obligations of friendship necessitate believing friends, at least in the context of their beliefs and claims about themselves (e.g. Keller, 2004). While the case of trusting information about objective facts like labels is different, such moral considerations may still compel people to condone believing information from friends. A separate ambiguity in adult responses from Experiment 1 stems from its third-person nature. A prediction about what a third party will do does not tell us what the participant themselves would do when faced with such a situation. One possibility is that people would see themselves as acting similarly to what they predicted for Maya. Alternatively, they may see themselves as acting differently than Maya. Experiment 3 addresses both of these questions. In a betweensubjects design, we asked some participants what Maya should do, and others what they would 
do if they were in Maya's place. As we were particularly interested in judgments about an inaccurate friend, the friend was presented as inaccurate in both conditions.

\section{Method}

Participants. Sixty-four participants from the United States $(M=33$ years, 31 female, $78 \%$ White, $1.5 \%$ Black, $8 \%$ Asian, $12.5 \%$ mixed-race or other) were recruited from Prolific.

Materials. The study was designed as a Qualtrics survey. The same videos and pictures from Experiment 1 were used.

Design. Half the participants were randomly assigned to the Prescriptive condition, while the other half were assigned to the Vicarious condition.

Procedure. The procedure was similar to Experiment 1, with some notable differences.

Familiarization phase. Participants first watched the Introduction video in which Maya introduced herself and the other two individuals. Then, participants in the Vicarious condition received the Vicarious manipulation, in which they saw pictures of the characters and were asked to place themselves in Maya's shoes. They had to imagine that Jenny was their friend who they had known for a long time, and Sophie was someone they had just met. Then, all participants watched the Naming video, in which the friend and stranger named four everyday objects. For all participants, the friend provided wrong responses and the stranger provided correct ones. Following these sections, memory questions were asked to check if participants recalled the relationships. These were worded differently across the two conditions (Prescriptive: "Which one is Maya's best friend?" Vicarious: "Which one is your best friend?"). Like before, we also checked memory of prior accuracy. If a participant did not recall the manipulation correctly, they were shown the corresponding video (introduction or naming) again.

Test phase. There were three sets of questions in the test phase.

1. Ask and Endorse (6 trials). This was similar to Experiment 1, meaning that Maya brought out a novel object and wondered what its name was. The friend and stranger then 
offered two competing novel labels. In the Prescriptive condition, we asked what Maya should do (Ask question: "Who should Maya ask?" Endorse question: "What should Maya call this?"). In the Vicarious condition, we asked what the participant would do if they were in Maya's place (Ask question: "Who will you ask?" Endorse question: "What will you call this?").

2. Social preference (6 trials). In the Prescriptive condition, we asked participants who Maya liked best, preferred to share with, and help. In the Vicarious condition, we asked the same questions about the participant themselves.

3. Justification (1 trial). Participants saw a new novel item and endorsed a label for it after seeing the friend and stranger offer their labels. They then explained their choice.

\section{Results}

Familiarization phase. Participants in both conditions remembered the identity of the friend and stranger (Prescriptive condition: 94\%, Vicarious condition: 91\%), and who had given correct and wrong labels for objects (Prescriptive condition: 81\%, Vicarious condition: 97\%).

\section{Test phase.}

1. Ask and Endorse. Participants chose the friend $11 \%$ of the time in the Prescriptive condition, compared to $20 \%$ in the Vicarious condition. Responses in both conditions were significantly below chance (Prescriptive condition: $p=0.001$, Vicarious condition: $p=0.0003$ ), and there was no difference between the two conditions.

2. Social preference. Participants chose the friend on average for $88.5 \%$ of trials in the Prescriptive condition, and for $45.8 \%$ of trials in the Vicarious condition. These rates were significantly different from each other $(\mathrm{OR}=0.05 ; 95 \% \mathrm{Cl}=0.01,0.15 ; p<0.0001)$, and while responses in the Prescriptive condition were significantly above chance $(p<0.00001)$, they were at chance for the Vicarious condition $(p=0.5)$.

3. Justification. The majority of justifications appealed to accuracy (Prescriptive condition: $81.3 \%$, Vicarious condition: $53.1 \%$ ), and there was no difference between the two conditions $(p=0.21)$. See Appendix A for more details. 


\section{Discussion}

Across Experiments 1 and 3, we found that adults think that 1) others will tend to believe their friends even if they are inaccurate, 2) others should not trust inaccurate friends, and 3) they themselves would not trust information from inaccurate friends. Thus, adults think others, unlike themselves, are inappropriately trusting of their friends when they are not epistemically licensed to be. This may reflect a cynical view among adults toward the nepotistic belief acquisition of others. Alternatively, adults may think they would not believe inaccurate friends but still fall short in their own practices. That is, the pull of trusting a friend in real life could mask epistemic concerns and leave a blind spot leading adults to think they are not biased towards believing friends when they actually are. If this is the case, their low levels of professed belief in the friend in the Vicarious condition may have been aspirational, rather than realistic. Regardless of which possibility is right, the vigilance shown in Experiment 1 in which adults mostly expected Maya to trust her inaccurate friend may be warranted. Although most responses favored trusting the accurate stranger, $20 \%$ of responses in the Vicarious condition (from 14 out of 32 participants) and 10\% in the Prescriptive condition (from 8 out of 32 participants) maintained trust in the inaccurate friend. These numbers could be viewed as a rough estimate of the proportion of occasions and individuals in which bias in inaccurate friends applies. That is, some individuals may be prone to believing their inaccurate friends some of the time, and a small number may be "super" believers, particularly prone or perhaps morally motivated to believe their friends outright, no matter what. Thus, even if most people turn out to be impervious to the friendship bias, the existence of a sizable minority who are not would merit and require widespread vigilance.

Finally, responses to the Social preference questions in the Vicarious condition were, somewhat surprisingly, significantly lower than those in the Prescriptive condition. It is unlikely that Vicarious condition participants forgot the identity of the friend and stranger, especially given the clear results from the other condition. Rather, it suggests that many in the Vicarious 
condition were unenthusiastic about a friend who was so inaccurate as to not know the names of everyday objects, and demonstrated this in their lack of preference for her as a social partner.

\section{General Discussion}

Through three experiments we found that 1) four- and five-year-old children did not think that people are predisposed to believe their friends, be it for labels or opinions, 2) for labels, which are objective, children valued accuracy from both perspectives. For opinions, which are subjective, accuracy did not play a role, 3) while perspective did not matter for children's judgements about labels or opinions, it did for social preferences, 4) adults expected people to be partial to their friends even when inaccurate but believed they should not be so, and factored accuracy into their own judgments both when answering as themselves and when putting themselves in Maya's shoes.

The findings suggest that children reason differently from adults with regard to possible biases in believing information from friends. Adults judged that even though other people should not trust their inaccurate friends, they will likely do so anyway. Interestingly, they made this prediction despite responding that they themselves would not trust an inaccurate friend. This suggests that adults take other people's favor towards their friends seriously, as an unfortunate trap that other people fall prey to (but not themselves). Our data from Experiment 3 further suggested that a considerable minority of respondents thought that they would or the main character should believe some information from the inaccurate friend. As a result, while adults' might exaggerate the rates at which others would likely favor close but dubious sources, they are not wrong that such practices exist. And their appreciation of such friendship-based biases probably serves their critical thinking well. By implication, preschoolers begin with the expectation that others value accuracy over partiality, and over time, observe (and experience) the favor that friends show to each other. It would be worthwhile for future work to consider the contexts or environments that foster the development of epistemic vigilance in the face of friendship, as well as those that foster partiality towards uninformed or misinformed friends. In 
an alternative light, preschoolers' reasoning may be justified for the time being because they and their peers do indeed value accuracy over partiality. Young children display a general tendency to value epistemic over social cues (Tong, Wang, \& Danovitch, 2019), and they shy away from their own social partners in favor of accurate informants when deciding who to trust (e.g. Corriveau et al., 2009; Corriveau \& Harris, 2009). This is especially warranted in the case of friendship as children are surrounded by peer friends who know little more than them. Children may often witness friends making assertions that they themselves know to be false or that turn out to be false when a teacher or parent weighs in. Hence, the strategy of seeing accuracy as important and friendship as less important may indeed match their experiences with both characteristics.

One notable aspect of the findings was that the accuracy of the friend or lack thereof did not bear on children's trust in her opinions. This happened despite the fact that children were unwilling to trust the same friend's testimony regarding labels. Going a step beyond opinions, we saw children seek information equally from the inaccurate friend and the accurate stranger elsewhere too. Regarding the Public knowledge questions in Experiment 1, children thought that the friend and stranger were equally fit to answer questions about general facts. In the Expert knowledge trials too, children thought either informant could be consulted about animals, fixing a toy, or new songs. It is possible that children thought that all adults would know general facts that were easily knowable and which indeed the children knew themselves (e.g. the color of frogs), or perhaps that the inaccurate friend deserved a chance to provide information in other domains (e.g. songs). Regardless, it provides indirect yet corroborating evidence that any penalization of the inaccurate friend was confined to the names of novel objects, part of a specific class of facts. The finding that children do not completely seal off themselves from those who make errors has been documented before. Koenig and Jaswal (2011) found that three- and four-year-olds did not expect a dog expert to be correct on the names of novel objects. Similarly, we find here that four- and five-year-olds do not expect an expert in naming 
objects (aka the stranger in the Inaccurate Friend condition) to be an expert on other topics. Further, Koenig and Jaswal (2011) found that children distrusted an inexpert who was clearly wrong about dogs when she offered labels for novel objects, which they termed a 'pitchfork' effect. However, we found that even when the friend was completely wrong on the labels of familiar objects, children were still choosing equally between her opinions and those of the stranger. The lack of a pitchfork effect in our findings may point to children's understanding of the subjective nature of opinions. What this signifies is that children may be open towards testimony from previously inaccurate informants when it is in the form of subjective opinions.

Another noteworthy aspect of the findings has to do with the issue of perspective taking. For several types of questions, we asked children to provide answers from their own perspective as well as from the main character's. We did not include children younger than four years in the study due to their lack of mastery over false belief tasks and the like (Wellman, Cross, \& Watson, 2001). Nevertheless, despite four- and five-year-olds' ability to engage in mentalizing and different variations on the theory of mind tasks, we found that children consistently responded similarly for themselves and Maya. The prominent exception to this rule was their higher levels of responses in favor of the friend when answering Social preference questions for Maya than for themselves. One possible explanation for these patterns is that the mentalizing aspect is too complex for preschoolers to handle, and that in spite of their ability to conceptualize others' mental states and apply it to social preferences, they are still unable to input perspective into further complicated inferences about belief. The possibility we favor is more charitable towards children's cognitive capacities, suggesting that they are in fact able to work perspective into reasoning about belief, but do not do so because they think it should not apply. In other words, children may genuinely think that Maya likes her friend more, but that Maya will not show that favor when evaluating her friend's novel claims or opinions.

This study departs from the classic trust in testimony paradigm in two key ways and in doing so makes novel contributions to the broader literature on social learning. First, we asked 
children to make judgments about others' selective learning decisions, as well as their own selective decisions. This allowed us to assess not only children's values in learning and decision making, but also their assessments of other people's values. Second, we asked children to choose an informant from whom to gain opinions, rather than labels. Although children answered from Maya's perspective similarly to their own, there may be domains or situations in which even this age group would better differentiate the first- and third-person perspectives. For instance, if asked to choose between information from their own mother and a friend's mother, children may prefer their mother but recognize that their friend would prefer their own mother. Using such manipulations on the trust in testimony paradigm can help chart out the development of critical thinking and evaluating information. Further, preschoolers clearly differentiated between labels and opinions and were willing to entertain opinions from an inaccurate informant. This finding speaks to the versatility of children's reasoning about the different types of statements that make their way from one individual to another. It would be worthwhile to investigate whether children view other types of non-factual statements (e.g. preferences, interpretations, beliefs) as more akin to labels or opinions.

Our findings also have implications for the burgeoning literature on friendship concepts. Preschoolers understand that affection is central to friendship (e.g. Furman \& Bierman, 1983), and here too, they expected Maya to like her friend as a social partner in both experiments. Nevertheless, they did not expect her to preferentially share with or help her friend in Experiment 1, which seems to go against preschoolers' expectation that friends share with and help one another (Liberman \& Shaw, 2017; Afshordi, 2019). However, the situation here is somewhat different because children know that Maya has met the stranger and seems to be positively inclined towards her (i.e. saying "She seems nice."). Therefore, some children may reason that Maya wants to ingratiate herself to this potential social partner or make her feel welcome. Thus, the current findings are still in alignment with friendship concepts and expectations as they apply to the domain of affection and prosocial actions. With regard to 
knowledge and information, however, the situation is murkier. Despite expecting friends to be likely to share secrets with each other (Liberman \& Shaw, 2018), preschoolers in our study did not think that friends would prefer labels or opinions offered by each other. Thus, the overall picture seems to be one in which preschoolers associate friendship with secrets, a relatively intimate type of information, but do not expect other, more general types of information like labels and opinions to be favored between friends. Somewhat surprisingly, personal information (e.g. favorite color) seems to fall within this latter category as well, meaning that the boundary of information that is associated with friendship is quite restricted in the preschool period.

The current study was limited in a number of ways. First, data collection was hampered by the coronavirus breakout, and we collected data online from half of the sample in Experiment 2. The change was not ideal, but we did our best and believe we succeeded in making the experiment comparable across in-person and online testing. In fact, we saw somewhat better memory from online participants than from in-person ones, signalling that the integrity of the manipulations in the procedure was not compromised. Nonetheless, we found small although ultimately unimportant differences between the in-lab and online groups that are not easy to interpret. Second, we were unable to collect informative justifications for responses from children. We tried a number of approaches, but most children responded by saying "I don't know." Had we succeeded in eliciting justifications from children, we might have gained more insight into whether and when they considered friendship as possible grounds for trust. Further, due to logistical limitations, our samples of children and adults were racially homogenous. Although we do not claim that the findings would have been necessarily different had our sample been more balanced, we regret the lack of representation.

Future work should explore whether older children respond differently from preschoolers and when they begin to show adultlike inferences. We chose the older preschool ages because of children's rich concepts of friendship and the considerable body of work on selective learning. As a result, our findings speak to and contribute to ongoing scholarship on the tensions between 
interpersonal and epistemic grounds for trust in that age group (Harris, Koenig, Corriveau \& Jaswal, 2018; Koenig, Li \& McMyler, 2021). Nevertheless, an expanded age range would clarify the developmental trajectory in understanding of trust in friends. Future work should also consider other types of close relationships. Given that children are swayed by testimony from their mother or a familiar teacher, it would be interesting to find out if they expect bias in favor of these individuals for others.

The testimony of others has the power to inform us, to educate us, and to make us aware of a world much bigger than the one we inhabit in our daily lives. Remarkable feats of human culture are made possible by our ability to put our trust into the veracity of what others tell us. However, testimony can also mislead us, warping our reality, spreading falsehoods, and making us wary of non-existent dangers. As our findings from Experiment 3 suggest, some individuals seem more prone than others in believing their friends, even when they are clearly poor sources of information. Not surprisingly, then, adults seem to factor partiality into their judgments (Experiment 1), expecting others to be biased to believe their friends, and they presumably use this expectation to remain skeptical about information that others have procured from their friends. Preschoolers, meanwhile, seem to expect a more rational path to belief for others, thinking that they, like themselves, would be credulous of information coming from an inaccurate friend. Indeed, despite the impressive skepticism that preschoolers show towards epistemically questionable sources, they seem less sensitive to the risks that partiality or interpersonal biases can create for learners. Thus, the developmental trajectory of expecting epistemic biases in favor of friends is only just starting in the preschool years. 


\section{References}

Afshordi, N. (2019). Children's Inferences About Friendship and Shared Preferences Based on Reported Information. Child Development, 90(3), 719-727. https://doi.org/10.1111/cdev.13237

Afshordi, N., \& Liberman, Z. (2020). Keeping friends in mind: Development of friendship concepts in early childhood. Social Development. https://doi.org/10.1111/sode.12493

Corriveau, K. H., Harris, P. L., Meins, E., Fernyhough, C., Arnott, B., Elliott, L., ... \& De Rosnay, M. (2009). Young children's trust in their mother's claims: Longitudinal links with attachment security in infancy. Child Development, 80(3), 750-761. https://doi.org/10.1111/j.1467-8624.2009.01295.x

Corriveau, K., \& Harris, P. L. (2009). Choosing your informant: Weighing familiarity and recent accuracy. Developmental Science, 12(3), 426-437. https://doi.org/10.1111/j.14677687.2008.00792.x

Dunn, J. (1993). Young children's close relationships: Beyond attachment. Sage.

Elashi, F. B., \& Mills, C. M. (2014). Do children trust based on group membership or prior accuracy? The role of novel group membership in children's trust decisions. Journal of Experimental Child Psychology, 128, 88-104. https://doi.org/10.1016/j.jecp.2014.07.003

Feldman, S. (2003). Enforcing social conformity: A theory of authoritarianism. Political Psychology, 24(1), 41-74. https://doi.org/10.1111/0162-895X.00316

Feldman, S., \& Stenner, K. (1997). Perceived threat and authoritarianism. Political Psychology, 4, 741-770. https://doi.org/10.1111/0162-895X.00077

Furman, W., \& Bierman, K. L. (1983). Developmental changes in young children's conceptions of friendship. Child Development, 54, 549-556. https://doi.org/10.2307/1130041

Gelman, S. A. (2009). Learning from others: Children's construction of concepts. Annual Review of Psychology, 60, 115-140. https://doi.org/10.1146/annurev.psych.59.103006.093659 
Gottman, J. M. (1983). How children become friends. Monographs of the Society for Research in Child Development, 48(3), 1-86. https://doi.org/10.2307/1165860

Harris, P. L., Koenig, M. A., Corriveau, K. H., \& Jaswal, V. K. (2018). Cognitive foundations of learning from testimony. Annual Review of Psychology, 69, 251-273. https://doi.org/10.1146/annurev-psych-122216-011710

Hartup, W. W. (2006). Relationships in early and middle childhood. In A. L. Vangelisti, \& D. Perlman (Eds.), The Cambridge Handbook of Personal Relationships, (pp. 177-190). Cambridge University Press.

Hornsey, M. J., Harris, E. A., \& Fielding, K. S. (2018). The psychological roots of antivaccination attitudes: A 24-nation investigation. Health Psychology, 37(4), 307. 10.1037/hea0000586

Howes, C. (1988). Peer interaction of young children. Monographs of the Society for Research in Child Development, 53 (1, Serial No. 217). https://doi.org/10.2307/1166062

Howes, C. (2009). Friendship in early childhood. In K.H. Rubin, W.M. Bukowski, \& B. Laursen (Eds.), Handbook of peer interactions, relationships, and groups (pp. 180-194). Guilford Press.

Keller, S. (2004). Friendship and belief. Philosophical Papers, 33(3), 329-351. https://doi.org/10.1080/05568640409485146

Kinzler, K. D., Corriveau, K. H., \& Harris, P. L. (2011). Children's selective trust in nativeaccented speakers. Developmental Science, 14(1), 106-111. https://doi.org/10.1111/j.1467-7687.2010.00965.x

Koenig, M. A., Li, P. H., \& McMyler, B. (in press). Interpersonal Trust in Communication: The Case of Child Learners. Mind and Language.

Koenig, M. A., \& Harris, P. L. (2005). Preschoolers mistrust ignorant and inaccurate speakers. Child Development, 76(6), 1261-1277. https://doi.org/10.1111/j.1467-8624.2005.00849.x 
Koenig, M. A., Clément, F., \& Harris, P. L. (2004). Trust in testimony: Children's use of true and false statements. Psychological Science, 15(10), 694-698. https://doi.org/10.1111/j.0956-7976.2004.00742.x

Koenig, M. A., Tiberius, V., \& Hamlin, J. K. (2019). Children's judgments of epistemic and moral agents: From situations to intentions. Perspectives on Psychological Science, 14(3), 344-360. https://doi.org/10.1177/1745691618805452

Koenig, M. A., \& Jaswal, V. K. (2011). Characterizing children's expectations about expertise and incompetence: Halo or pitchfork effects?. Child Development, 82(5), 1634-1647. https://doi.org/10.1111/j.1467-8624.2011.01618.x

Lane, J. D., Wellman, H. M., \& Gelman, S. A. (2013). Informants' traits weigh heavily in young children's trust in testimony and in their epistemic inferences. Child Development, 84, 1253-1268. doi: 10.1111/cdev.12029

Li, P. H., \& Koenig, M. A. (2020). Children's Evaluations of Informants and their Surprising Claims in Direct and Overheard Contexts. Journal of Cognition and Development, 21(3), 425-446. https://doi.org/10.1080/15248372.2020.1745208

Liberman, Z. (2020). Keep the cat in the bag: Children understand that telling a friend's secret can harm the friendship. Developmental Psychology. 56(7), 1290-1304. https://doi.org/10.1037/dev0000960

Liberman, Z., \& Shaw, A. (2017). Children use partial sharing as a cue to friendship. Journal of Experimental Child Psychology, 159, 97-109. https://doi.org/10.1016/j.jecp.2017.02.002

Liberman, Z., \& Shaw, A. (2018). Secret to friendship: Children make inferences about friendship based on secret sharing. Developmental Psychology, 54, 2139-2151. https://doi.org/10.1037/dev0000603

Liberman, Z., \& Shaw, A. (2020). Even his friend said he's bad: Children think personal alliances bias gossip. Cognition, 204, 104376. https://doi.org/10.1016/j.cognition.2020.104376 
Liberman, Z., Gerdin, E., Kinzler, K. D., \& Shaw, A. (2020). (Un) common knowledge: Children use social relationships to determine who knows what. Developmental Science, e12962. https://doi.org/10.1111/desc.12962

Many trust what their friends post on social media more than experts, poll claims (2019). Independent.https://www.independent.co.uk/extras/lifestyle/social-media-facebookfriends-trust-experts-a9015636.html

Mesoudi, A., \& Thornton, A. (2018). What is cumulative cultural evolution? Proceedings of the Royal Society B: Biological Sciences, 285(1880), 20180712. https://doi.org/10.1098/rspb.2018.0712

Mills, C. M., \& Grant, M. G. (2009). Biased decision-making: Developing an understanding of how positive and negative relationships may skew judgments. Developmental Science, 12(5), 784-797. https://doi.org/10.1111/j.1467-7687.2009.00836.x

Mills, C. M., Al-Jabari, R. M., \& Archacki, M. A. (2012). Why do people disagree? Explaining and endorsing the possibility of partiality in judgments. Journal of Cognition and Development, 13(1), 111-136. https://doi.org/10.1080/15248372.2010.547236

O'Connor, C., \& Weatherall, J. O. (2019). The misinformation age: How false beliefs spread. Yale University Press.

Olson, K. R., \& Spelke, E. S. (2008). Foundations of cooperation in young children. Cognition, 108(1), 222-231. https://doi.org/10.1016/j.cognition.2007.12.003

Paluck, E. L. (2011). Peer pressure against prejudice: A high school field experiment examining social network change. Journal of Experimental Social Psychology, 47(2), 350-358. https://doi.org/10.1016/j.jesp.2010.11.017

R Core Team (2020). R: A language and environment for statistical computing. R Foundation for Statistical Computing, Vienna, Austria. URL http://www.R-project.org/ 
Reifen Tagar, M., Federico, C. M., Lyons, K. E., Ludeke, S., \& Koenig, M. A. (2014). Heralding the authoritarian? Orientation toward authority in early childhood. Psychological Science, 25(4), 883-892. https://doi.org/10.1177\%2F0956797613516470

Sheskin, M., \& Keil, F. (2018). TheChildLab. com A video chat platform for developmental research. Retrieved from https://psyarxiv.com/rn7w5

Sobel, D. M., \& Finiasz, Z. (2020). How children learn from others: An analysis of selective word learning. Child Development, 91(6), e1134-e1161. https://doi.org/10.1111/cdev.13415

Taylor, S., Landry, C. A., Paluszek, M. M., Groenewoud, R., Rachor, G. S., \& Asmundson, G. J. (2020). A proactive approach for managing COVID-19: The importance of understanding the motivational roots of vaccination hesitancy for SARS-CoV2. Frontiers in Psychology, 11, 2890. https://doi.org/10.3389/fpsyg.2020.575950

Tomasello, M. (2016). Cultural learning redux. Child Development, 87(3), 643-653. https://doi.org/10.1111/cdev.12499

Tong, Y., Wang, F., \& Danovitch, J. (2020). The role of epistemic and social characteristics in children's selective trust: Three meta-analyses. Developmental Science, 23(2), e12895. https://doi.org/10.1111/desc.12895

Wellman, H. M., Cross, D., \& Watson, J. (2001). Meta-analysis of theory-of-mind development: The truth about false belief. Child Development, 72(3), 655-684. https://doi.org/10.1111/1467-8624.00304 


\section{Appendix A}

\section{Justifications from Experiment 1}

It should be noted that we attempted to collect justifications from children, but the question was difficult to convey and most children seemed confused by it. After trying several different wordings, we removed the question from the procedure. Thus, we only report data from adults. Adults endorsed the labels provided by the friend at similar rates to their overall Ask and Endorse responses (Friendship-Maya: 90.6\%, Friendship-Self: 40.6\%; Inaccurate Friend-Maya: $62.5 \%$, Inaccurate Friend-Self: $12.5 \%$ ). Their justifications were coded into three main categories:

1) Accuracy: These responses mentioned an informant's accuracy or lack thereof, e.g. "Because she has accurately named the un made up items."

2) Friendship: The participant referred to Maya's friendship with Jenny, e.g. "Because Jenny is her best friend and Maya would trust her opinion more than that of Sophie."

3) Other: All other responses that were unrelated to accuracy or friendship concerns,

e.g. "Because she answered first.", "It sounds better.", "She did not hesitate to produce a name for it, she sounded very confident."

Figure A-1 shows the rate of justifications in each category depending on the condition, perspective, and whether the participants had endorsed the label from the friend or the stranger. In the Friendship condition, justifications for participants' own response were predominantly in the Other category $(88 \%)$, unrelated to accuracy or friendship regardless of whether they chose the Friend or the Stranger. However, $82 \%$ of the same participants appealed to friendship when providing justifications from Maya's perspective. In the Inaccurate Friend condition, participants' mainly endorsed the stranger from their own perspective, and their justifications mentioned accuracy (84\%). When answering from Maya's perspective, those who thought Maya would trust her friend unanimously talked about friendship (100\%), while those who thought Maya would trust the stranger mentioned accuracy (92\%). Since $62.5 \%$ thought Maya would trust her 
friend, the majority of overall justifications for Maya's trust in the Inaccurate friend condition favored friendship (62\%).

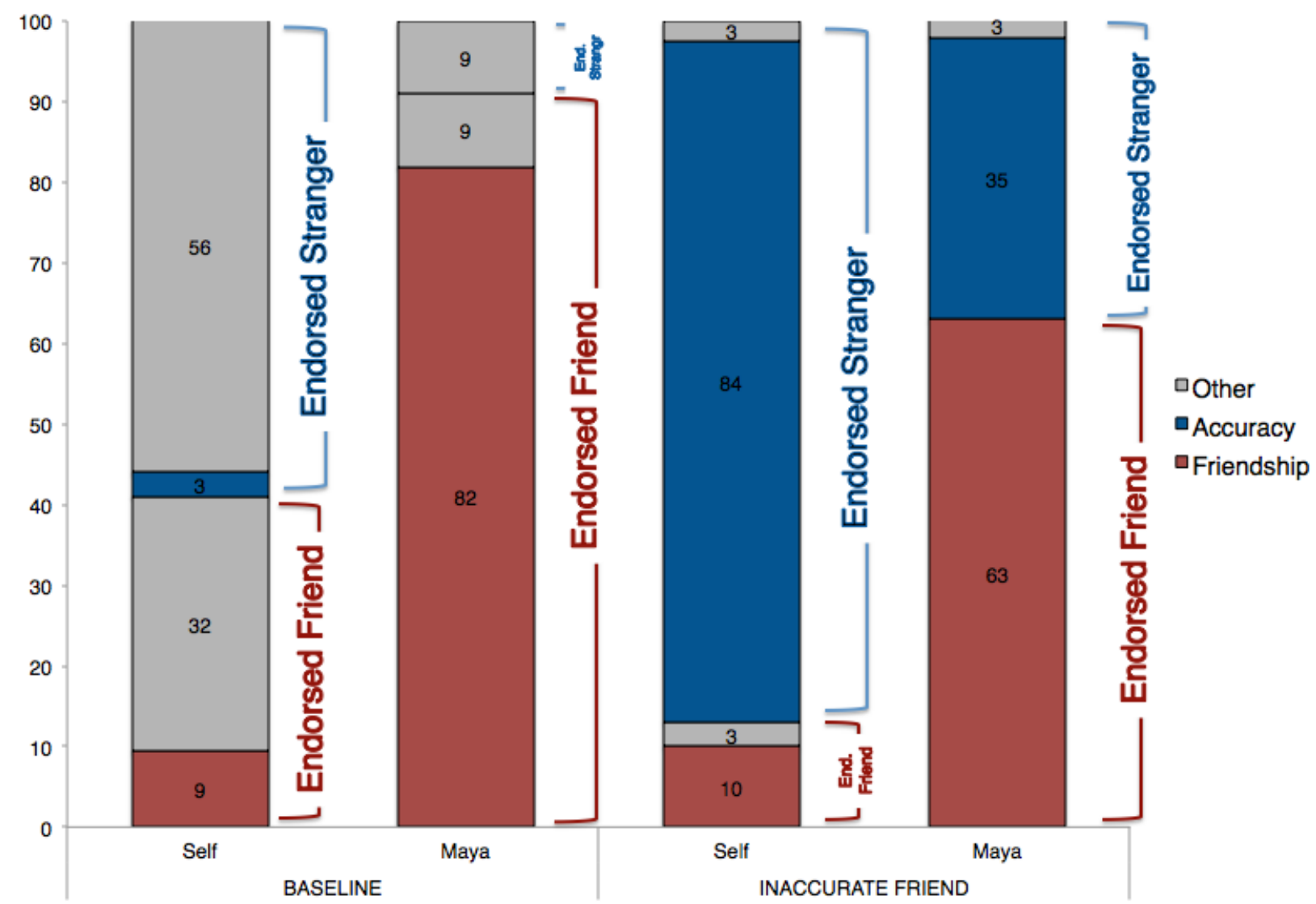

Figure A-1. Justifications for endorse responses from adults in Exp. 1, separated by condition and perspective. Within each perspective, responses are further divided depending on whether the friend or stranger had been endorsed.

A chi-square test compared the number of Friendship and Accuracy justifications between the self and Maya perspective and found a significant difference $\left(X^{2}(1, N=91)=\right.$ 34.58, $p<0.00001)$. In short, adults explained Maya's trust in the friend by appealing to friendship in both the Friendship and Inaccurate Friend conditions. Meanwhile, they were more likely to explain their own trust in terms of accuracy.

\section{Justifications from Experiment 3}


Responses to the endorse question for the justification item in Experiment 3 were comparable to the Ask and Endorse learning responses from the same experiment $(12.5 \%$ in the Prescriptive condition, and $21.9 \%$ in the Vicarious condition). The majority of justifications in the Prescriptive condition referred to accuracy (81.3\%), while the remaining were divided between Friendship (6.3\%) and Other (12.5\%). In the Vicarious condition, a little over half of justifications were about Accuracy (53.1\%), some were about Friendship (12.5\%) and the remaining third were irrelevant (i.e. Other, 34.4\%). A chi-square test comparing rates of Accuracy and Friendship justifications between the two conditions did not find a significant difference $\left(X^{2}(1, N=49)=1.58, p=0.21\right)$. 